\title{
In Vivo Regulation of Human Skeletal Muscle Gene Expression by Thyroid Hormone
}

\author{
Karine Clément, ${ }^{1,6}$ Nathalie Viguerie, ${ }^{2}$ Maximilian Diehn, ${ }^{3}$ Ash Alizadeh, ${ }^{3}$ \\ Pierre Barbe, ${ }^{2}$ Claire Thalamas, ${ }^{4}$ John D. Storey, ${ }^{5}$ Patrick O. Brown, ${ }^{3}$ \\ Greg S. Barsh, 1,7 and Dominique Langin ${ }^{2,7}$ \\ ${ }^{1}$ Department of Pediatrics and Genetics, Howard Hughes Medical Institute, Beckman Center, Stanford University School \\ of Medicine, Stanford, California 94305, USA; ${ }^{2}$ Institut National de la Santé et de la Recherche Médicale Unit 317 , Louis \\ Bugnard Institute, Paul Sabatier University, Rangueil Hospital, 31403 Toulouse, France; ${ }^{3}$ Department of Biochemistry, \\ Howard Hughes Medical Institute, Beckman Center, Stanford University School of Medicine, Stanford, California 94305, \\ USA; ${ }^{4}$ Clinical Investigation Center, Purpan Hospital, Pavillon Riser, 31059 Toulouse, France; ${ }^{5}$ Department of Statistics, \\ Stanford University, Stanford, California 94305, USA
}

\begin{abstract}
Thyroid hormones are key regulators of metabolism that modulate transcription via nuclear receptors. Hyperthyroidism is associated with increased metabolic rate, protein breakdown, and weight loss. Although the molecular actions of thyroid hormones have been studied thoroughly, their pleiotropic effects are mediated by complex changes in expression of an unknown number of target genes. Here, we measured patterns of skeletal muscle gene expression in five healthy men treated for 14 days with $75 \mu \mathrm{g}$ of triiodothyronine, using 24,000 cDNA element microarrays. To analyze the data, we used a new statistical method that identifies significant changes in expression and estimates the false discovery rate. The 381 up-regulated genes were involved in a wide range of cellular functions including transcriptional control, mRNA maturation, protein turnover, signal transduction, cellular trafficking, and energy metabolism. Only two genes were down-regulated. Most of the genes are novel targets of thyroid hormone. Cluster analysis of triiodothyronine-regulated gene expression among 19 different human tissues or cell lines revealed sets of coregulated genes that serve similar biologic functions. These results define molecular signatures that help to understand the physiology and pathophysiology of thyroid hormone action.
\end{abstract}

[The list of transcripts corresponding to up-regulated and down-regulated genes is available as a web supplement at http:/ / www.genome.org.]

Thyroid hormones control essential functions in development and metabolism. The importance of the thyroid was recognized in the 19th century when an enlargement of the gland in hyperthyroidism was found to be associated with heart dysfunction, exophthalmos, and increased metabolic rate (Harrington 1935; Dauncey 1990). The isolation of thyroxine, and later of triiodothyronine (T3) a much more active molecule, resulted in a better understanding of the pleiotropic effects of the hormones and their therapeutic use. The major effects of thyroid hormones are mediated by modulation of gene transcription. Most of the characterized thyroid response elements in target genes are positive cis-acting elements at which gene transcription is repressed by unliganded thyroid hormone receptors (TRs) and activated by T3occupied TRs (Wu and Koenig 2000; Zhang and Lazar 2000). In the presence of ligand, the TR undergoes a conformational change, which results in the replacement of a corepressor

6Present address: Laboratoire et Service de Médecine et Nutrition, EA Université Paris 6, Hôtel-Dieu, Place du Parvis NotreDame 75004 Paris, France.

${ }^{7}$ Corresponding authors.

E-MAIL langin@toulouse.inserm.fr; FAX (33)-5-62172950.

E-MAIL gbarsh@cmgm.stanford.edu; FAX (650) 723-1399.

Article and publication are at http://www.genome.org/cgi/doi/10.1101/ gr.207702. complex by a coactivator complex. The coactivator histone acetyltransferase activity leads to an open transcriptionally active chromatin state. The recruitment of the TR-associated protein complex may constitute a subsequent step in transcriptional activation by T3. In the absence of ligand, the heterodimer interacts with a corepressor complex with histone deacetylase activity. Histone deacetylation and DNA methylation both lead to transcriptional repression.

Although much has been learned about the molecular mechanisms of thyroid hormone action, a limited number of target genes has been identified. Most studies have focused on rodent liver (Feng et al. 2000). A large-scale profile of thyroid hormone transcriptional effects in vivo never has been undertaken in humans. In adults, thyroid hormones have a marked thermogenic effect and promote weight loss (Freake and Oppenheimer 1995; Rooyackers and Sreekumaran Nair 1997). Skeletal muscle is an important target of thyroid hormone action. It accounts for most of the variation in metabolic rate between individuals and plays a crucial role in protein metabolism (Zurlo et al. 1990). Here, we report the application of cDNA microarray technology to study the effect of thyroid hormone in vivo on human skeletal muscle. We defined a transcriptional profile of 383 genes regulated by T3. Most of these genes are novel targets of thyroid hormone. They belong to functional classes that explain the effect of T3 on protein turnover and energy metabolism. The data also 
reveal new mechanisms for the biologic action of T3, extending well beyond the classic metabolic effect of the hormone.

\section{RESULTS AND DISCUSSION}

\section{In Vivo Treatment with Triiodothyronine and Use of cDNA Microarray on Skeletal Muscle mRNA}

Nine healthy men received $75 \mu \mathrm{g} / \mathrm{d}$ of T3 for 14 days (Table 1 ). The treatment induced a 1.7-fold increase in free T3 levels. Free T4 levels and thyroid-stimulating hormone levels were decreased. The T3 treatment did not significantly modify body weight, fat mass, or lean body mass. Changes in gene expression induced by T3 therefore could be monitored independently of changes in body composition. Consistent with the well-known effect of thyroid hormones on energy expenditure, resting metabolic rate expressed in kilocalories per day or adjusted for lean body mass was increased by $13 \%$ and $15 \%$, respectively. The respiratory quotient was decreased. As expected, heart rate and systolic (but not diastolic) blood pressure were increased by thyroid hormones.

Microbiopsies of vastus lateralis skeletal muscle were performed before and after the treatment. For microarray experiments, we used samples from five subjects. After amplification of total RNA (Wang et al. 2000a), fluorescently labeled cDNA was prepared from each experimental sample. For each subject, probes from basal and T3 treatment conditions labeled with cyanine (Cy) 3 or Cy5 dyes were hybridized to cDNA microarray. After a filtering procedure to eliminate badquality spots and background correction, $\log _{2}$ transformed data for each experiment were normalized and centered to the mean. Quantitative RT-PCR assays were performed on total RNA from eight subjects, of which four were not included in the microarray experiments.

\section{Analysis of High-Density Microarray Data}

We wanted to detect genes that show a statistically significant change in expression during thyroid hormone treatment.

Table 1. Clinical Data of Nine Healthy Men before and during Triiodothyronine Treatment

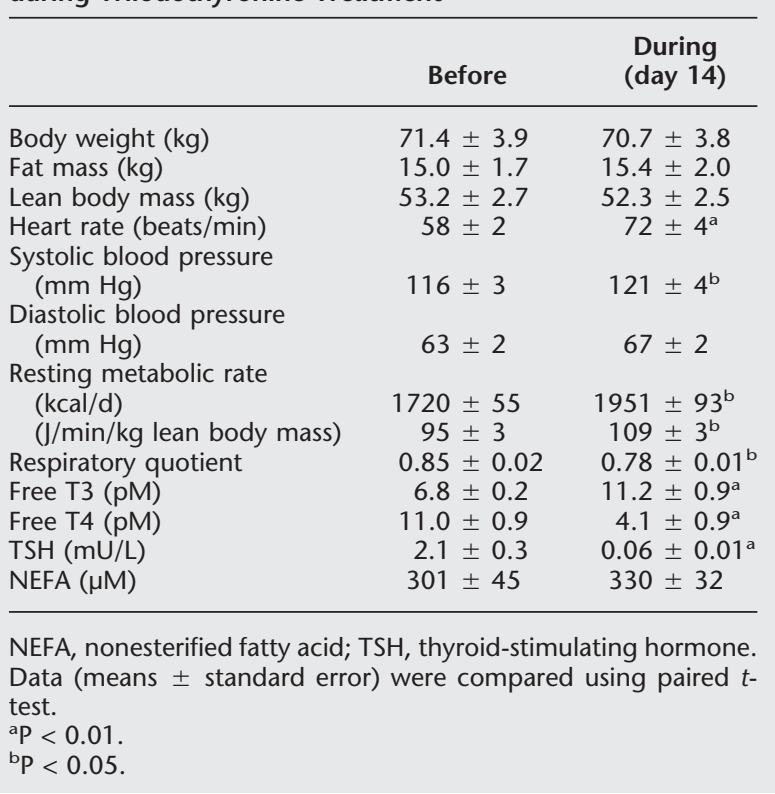

Most methods that have been used to analyze microarrays do not assess the degree to which significant changes in gene expression occurred by chance. Significant analysis of microarray (SAM) is a statistical method for accomplishing this task (Tusher et al. 2001). If there is no change due to treatment, then the true mean $\log _{2}$ ratio among the samples should be zero. Thus, we performed a t-statistic for each gene that tests whether the true mean is zero. SAM is a nonparametric method that decides how to call genes significant, and what the multiple testing error measure is for each significance region. The error measure is the expected proportion of falsepositives among all genes called significant, called the false discovery rate (FDR). The SAM procedure was performed on 18,705 cDNAs for which signals were recovered in the five subjects. We found $21 \mathrm{cDNAs}$ with estimated FDR of $<0.1 \%$, 98 with estimated FDR $<10 \%$ and 449 with estimated FDR $<15 \%$.

Among the 449 cDNAs, 295 cDNAs were uniquely represented on the microarray. On the remaining 154 cDNAs, replicates were found within the $18,705 \mathrm{cDNAs}$. For all replicates corresponding to the same UniGene number, we tested, using Student's $t$-test, whether the expected value of the $\log _{2}$ ratio was 0 . On the 133 genes with replicates, 88 genes showed consistent regulation by T3 for the various cDNAs $(P<0.05)$. It must be stressed that this selection procedure is stringent. Each of the mRNA variants of a gene produced by alternative promoters or splicing or polyadenylation sites has the same UniGene number but is not necessarily identically regulated by T3. The list of the 403 transcripts corresponding to 381 up-regulated and two down-regulated genes is presented as a Supplementary Information Table (available as an online supplement at http://www.genome.org). The up-regulated genes showed a mean fold change above 1.43. To test the validity of the array experiments and SAM procedure, we performed real-time quantitative RT-PCR on six genes. Five of the genes were selected randomly among the genes with greater than twofold up-regulation. The sixth gene encodes uncoupling protein 3 that was shown to be up-regulated by T3 in skeletal muscle (Gong et al. 1997; Barbe et al. 2001). For each gene, the data from quantitative RT-PCR confirmed the array data (Table 2).

Reconstruction of the human skeletal muscle transcriptional profile has revealed a set of $\sim 400$ genes highly expressed or specific of skeletal muscle (Pietu et al. 1999; Bortoluzzi et al. 2000). Two hundred forty-seven genes were represented on the array. We found that $42(17 \%)$ genes were regulated by T3, showing the critical impact of thyroid hormone on genes characteristic of skeletal muscle. Because we assessed a large fraction of the transcriptome using high-density microarrays, the selected genes may reflect the main pathways regulated by T3 in human skeletal muscle. We assigned genes induced by T3 into functional categories (Table 3). We used Gene Ontology annotations available for $6331 \mathrm{cDNAs}$ represented on the array to calculate the percentages of genes in each functional category and compared them with the percentages obtained for T3-regulated genes. Figure 1 shows that some categories are more represented in the T3-regulated gene group indicating that thyroid hormone has profound impact on these cellular pathways. Finally, to determine whether T3-regulated genes shared common patterns of expression, cluster analysis of the 403 transcripts was performed among 19 different human tissues and cell lines using a hierarchical clustering method (Eisen et al. 1998). Interestingly, a significant fraction of genes from functional categories highly regulated by T3, 
Table 2. Fold Change of Human Skeletal Muscle mRNA Levels during Triiodothyronine Treatment

\begin{tabular}{|c|c|c|c|}
\hline UniGene no. & Encoded protein & Microarray & $\begin{array}{l}\text { Quantitative } \\
\text { RT-PCR }\end{array}$ \\
\hline Hs. 21537 & Protein phosphatase 1 , catalytic subunit, $\beta$ isoform & 3.04 & $2.30 \pm 0.45^{\mathrm{a}}$ \\
\hline Hs. 80595 & $\mathrm{NADH}$ dehydrogenase (ubiquinone) Fe-S protein 5 & 2.54 & $1.54 \pm 0.20^{\mathrm{b}}$ \\
\hline Hs. 131255 & Ubiquinol-cytochrome $\mathrm{c}$ reductase binding protein & 2.46 & $3.08 \pm 0.89^{b}$ \\
\hline Hs. 118836 & Myoglobin & 2.38 & $2.10 \pm 0.52^{b}$ \\
\hline Hs. 101337 & Uncoupling protein 3 & 2.30 & $4.31 \pm 1.44^{b}$ \\
\hline Hs. 111779 & Secreted protein acidic and rich in cysteine (SPARC) & 2.10 & $1.99 \pm 0.40^{\mathrm{b}}$ \\
\hline
\end{tabular}

such as energy metabolism, protein catabolism, protein synthesis, and ribonucleoprotein and RNA metabolism, is coexpressed in human tissues (Fig. 2). This suggests that thyroid hormone may participate in the transcriptional control of coregulated genes.

\section{Global View at mRNA Expression Changes Induced by T3}

A global view of the changes shows that thyroid hormone specifically affects many genes that are related to the physiological effects of the hormone on protein and energy metabolism (Table 3; Fig. 1). The largest fraction of regulated genes was involved in the transcriptional and post-

Table 3. Global Changes of Gene Expression Induced by Thyroid Hormone in Human Vastus Lateralis Skeletal Muscle

\begin{tabular}{|c|c|}
\hline Functional classes & $\begin{array}{c}\text { Number } \\
(\%)\end{array}$ \\
\hline $\begin{array}{l}\text { Transcriptional control } \\
\text { Transcription factors } \\
\text { Coactivators/corepressors } \\
\text { Histone (de)acetylation }\end{array}$ & $33(8.7)$ \\
\hline $\begin{array}{l}\text { Protein synthesis } \\
\text { Ribosomal proteins } \\
\text { Translation initiation factors }\end{array}$ & $14(3.7)$ \\
\hline $\begin{array}{l}\text { Glucose and lipid metabolism } \\
\text { Glycogen synthesis and glucose utilization }\end{array}$ & $8(2.1)$ \\
\hline $\begin{array}{l}\text { Signal transduction } \\
\text { Protein phosphatases } \\
\text { Protein kinases } \\
\text { G proteins } \\
\text { G protein-coupled receptors }\end{array}$ & $36(9.4)$ \\
\hline Cytoskeleton & $21(5.5)$ \\
\hline $\begin{array}{l}\text { Ribonucleoproteins and RNA metabolism } \\
\text { Pre-mRNA processing }\end{array}$ & $16(4.2)$ \\
\hline $\begin{array}{l}\text { Protein catabolism } \\
\text { Ubiquitin-proteasome pathway }\end{array}$ & $20(5.2)$ \\
\hline $\begin{array}{l}\text { Mitochondrial energy metabolism } \\
\text { Respiratory chain proteins } \\
\text { Mitochondrial carriers } \\
\text { Citric acid cycle }\end{array}$ & $22(5.8)$ \\
\hline $\begin{array}{l}\text { Cellular trafficking } \\
\text { Intracellular transport }\end{array}$ & $13(3.4)$ \\
\hline Cellular immunity & $9(2.4)$ \\
\hline Miscellaneous & $45(12)$ \\
\hline Expressed sequence tags & $144(38)$ \\
\hline
\end{tabular}

transcriptional control of protein synthesis. One-fourth of the genes was gathered in a gene cluster (Fig. 2A), indicating common regulatory mechanisms of transcription for these genes. In vivo, multiple mechanisms therefore can account for the control of protein levels by T3. T3 increases the expression of numerous factors involved in transcriptional control, premRNA processing, and protein translation (Table 3). Hence, protein synthesis may be promoted by thyroid hormone both directly through the direct effect of $\mathrm{T} 3$ on target gene promoters and indirectly through transcriptional control of proteins involved in transcriptional, post-transcriptional, and translational mechanisms (Fig. 3). Thyroid hormones are known to increase both skeletal muscle protein synthesis and degradation resulting in net protein breakdown (Rooyackers and Sreekumaran Nair 1997). Our data show a concomitant increase in mRNA expression of protein catabolism factors (Table 4). Most changes affected the ubiquitin/proteasome pathway, which is part of the non-lysosomal degradation of intracellular proteins. The protein turnover cluster (Fig. 2A) contained several subunits of the proteasome. Another important group

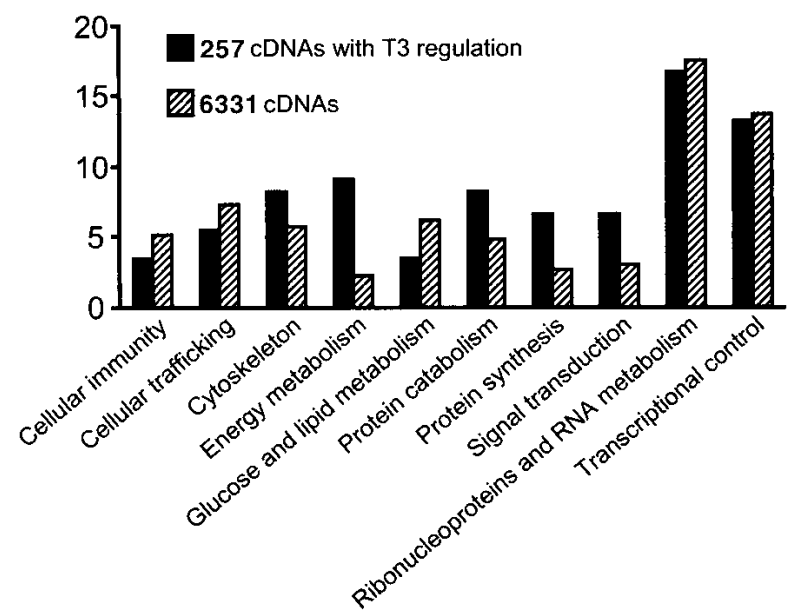

Figure 1 Impact of thyroid hormone on genes grouped in functional categories. Information on gene function was obtained from Gene Ontology annotations for 6331 cDNAs represented on the microarray. Among the genes regulated by thyroid hormone, information was available for 257 cDNAs. The cDNAs were classified into the functional categories defined in Table 1. Bars represent percentages in each category. 
A

A

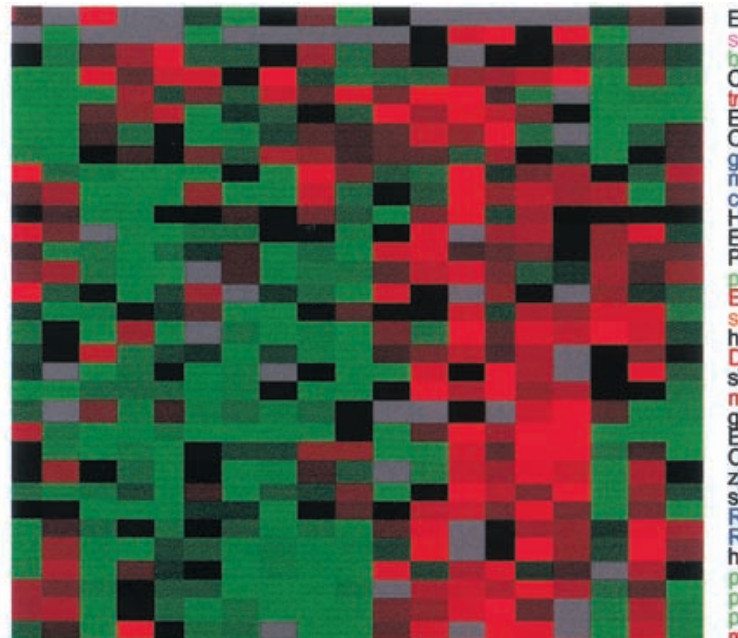

small nudear ribonucleoprotein D1 polypeptide (16kD)

rranched chain aminotransterase 2, mitochondna

CDK2-associated protein 1 Miscellaneous

transcription elongation factor B (Sili), polypeptide 2 (18kD, elongin B)

CDA14

guanine nucleotide binding protein ( $G$ protein), beta polypeptide 1

casein kinase 1, apha 1

Homo sapiens cDNAF J20738 fis,

PRDS 0149 protein

Proly encopenidase

Ewing sarooma breakpoint region 1

splicing factor, arginine/serine-nch 2

high-glucose-regulated protein

single-stranded DNA-binding protein 1

single-stranded DNA-binding
myogenic factor 6 (herculin)

CGts 65 protein

ainc fingerpin 146

signal recognition 146 particle $9 k D$

Ras-GTPase-activating protein SH3-domain-binding protein

Ras-GTPase-activating protein SH3-domain-binding protein

hypothetical protein FLJ21016

proteasome (prosome, macropain) subunit, alpha type, 3

proteasome prosome, macropain subunit, alpha type, 5

proteasome (prosome, macropesin

retinoblastoma-binding protein 4

heterogeneous nuclear ribonudeoprotein A2/B

$G$ protein-binding protein CRFG

hypothetical protein MGC5466

SET translocation (myeloid leukemia-associated)

RAD9 (S. pombe) homolog

mitochondrial nibosomal protein L3

small nudear ribonucleoprotein polypeptide E

eukaryotic transiation initiation factor $5 \mathrm{~A}$

proteasome (prosome, macropain) subunit, alpha type, 1

histone acetyltransferase .

high-mobility group (nonhistone chromosomal) protein 1

serine/ureonine kinase $17 \mathrm{a}$ (apoptosisinducing)

putative nucleic acid binding protein RY-1

unicine 5 monophosphat

CG-139 protein

Deleted in split-hand/split-foot 1 region

reticulocalbin 2, EF-hand calcium binding domain

cell division cycle 34

Ests

proinitin 10 los

ubiquilin 1 cytoskeleton protein

mitochondrial translational initiation factor 2

nudeoporin $88 \mathrm{kD}$

protein phosphatase 1, regulatory (inhibitor) subunit 2

IK cytokine, down-regulator of HLA II

hypothetical protein MGC4399

hypothetical protein FL 10618

hypothetical protein

yypothelcal protein FLJ13164

acety-Coenzyme A acetyitransferase 2 (acetoacetyl Coenzyme A thiolase)

COBW-like protein

regulatory factor X, 5 (influences HLA dass II expression)

Prader-Wilivangelman syndrome-5

smal nudear monucleoprotein polypepticle $A^{*}$

nucleophosmin (nucleolar phosphoprotein B23, numatrin)

heterogeneous nuclear nibonucepprotein A1

Ests

Ests
ribosom
Ests

Ests

nibosomal protein 527

ribos Ests

prothymosin, alpha (gene sequence 28 )

actin related protein $2 / 3$ complex, subunit 2 (34 kD)

H2A histone tamily, member Y

Ests

stromal antigen 2

cyclin M4

Homo sapiens, Similar to bromodomain-containing 4,

E2F transcription factor 3

IIA1 cylotoxic granule-associated RNA-binding protein-like 1

protein phosphatase 2 , regulatory subunit $B(B 56)$, gamma isoform

ucleosome assembly protein 1 -ike

eukaryotic transiation initiation factor 4 gamma, 3

eukaryouctinan

solute carrier family 2 (feclitated glucoseffructose transporter) member 5

phosphatidyinositol glycan, class $\mathrm{F}$

Wemer helicase interacting protein I
Protein translation

Signal transduction

Protein catabolism
Ribonucleoproteins and RNA metabolism

Transcription factors and cofactors

284 Genome Research

www.genome.org 
B

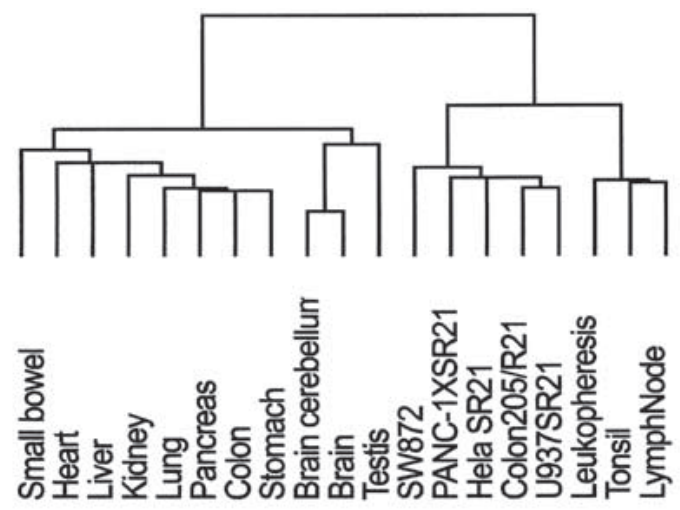

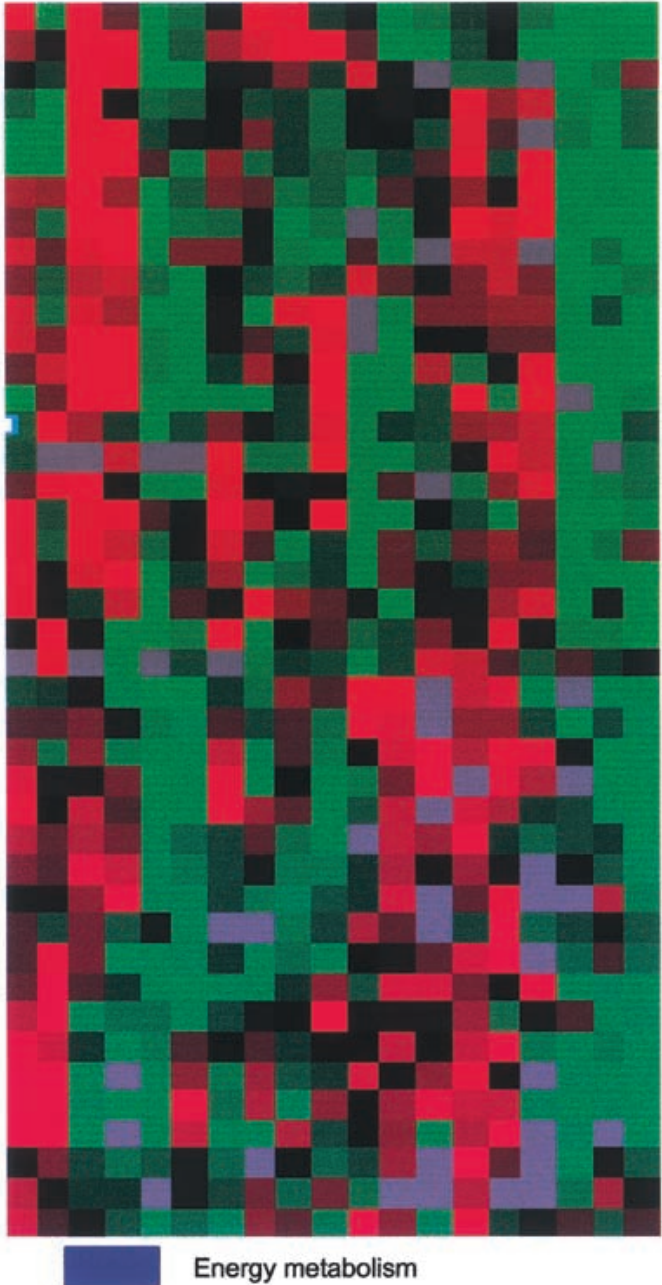

solute carrier family 25

proteasome (prosome, macropain) subunit, beta type, 9 putative secreted protein

Ests

mitochondrial ribosomal protein L33

NADH dehydrogenase (ubiquinone) Fe-S protein 5

ATP synthase, $\mathrm{H}+$ transporting, mitochondrial F0 complex, subunit F6

pyruvate dehydrogenase (lipoamide) alpha 1

ATP synthase, $\mathrm{H}+$ transporting, mitochondrial F1 complex

NADH dehydrogenase (ubiquinone) 1 beta subcomplex, 5

Ests

solute carrier family 25 member 3

esterase D/formylglutathione hydrolase

Ests

chromosome 21 open reading frame 4

Ests

cytochrome c oxidase subunit Vlc

Ests

cytochrome c oxidase subunit Vllic

succinate-CoA ligase, GDP-forming, alpha subunit

hypothetical protein

UDP-glucose pyrophosphorylase 2

steroid sulfatase (microsomal), arylsulfatase $\mathrm{C}$, isozyme $\mathrm{S}$

transcription elongation factor B (SIII), polypeptide 1-like

Ests

cytochrome c

cytochrome c

macrophage erythroblast attacher

chromosome $X$ open reading frame $1 \mathrm{~s}$

dihydrolipoamide dehydrogenase

Ests

hypothetical protein

mitochondrial ribosomal protein L19

superoxide dismutase 1 , soluble

glutamate dehydrogenase 1

GK001 protein

GTP-binding protein Sara

GTP-binding protein Sara

Williams-Beuren syndrome chromosome region 14

RAN binding protein 7

Ests

glutaredoxin 2

Figure 2 Two-dimensional clustering of 19 tissue experiments and 403 transcripts, which showed variation after triiodothyronine treatment. The set of genes were selected from the data matrix provided by the hybridization of 19 human tissues and cell lines to a common reference pool. Experiments and responsive genes were grouped by hierarchical clustering after centering the $\log _{2}$ ratios on the mean for all experiments. Each row represents a single gene and each column an experimental sample. For each sample, the ratio of the abundance of the transcripts of each gene to the mean abundance across all experiments is represented by the color of the corresponding cell in the matrix file. (green boxes) Transcript levels lower than the mean. (red boxes) Transcript levels higher than the mean. (black boxes) transcript level equal to the mean. (gray lines) missing data. Each node of the gene dendrogram was analyzed, and we focused on sets of genes clustered by functions. The upper dendrogram shows similarities in the expression pattern between tissues and cell lines. ( $A$ ) Protein turnover cluster. (B) Energy metabolism cluster.

of genes up-regulated by T3 encoded proteins of energy metabolism (Table 5). Search in PubMed (National Center for Biotechnology Information) showed that nine of these genes were positively regulated by thyroid hormone in various mammalian tissues. A cluster gathered 13 of the 22 mitochondrial proteins involved in energy metabolism (Fig. 2B). These 


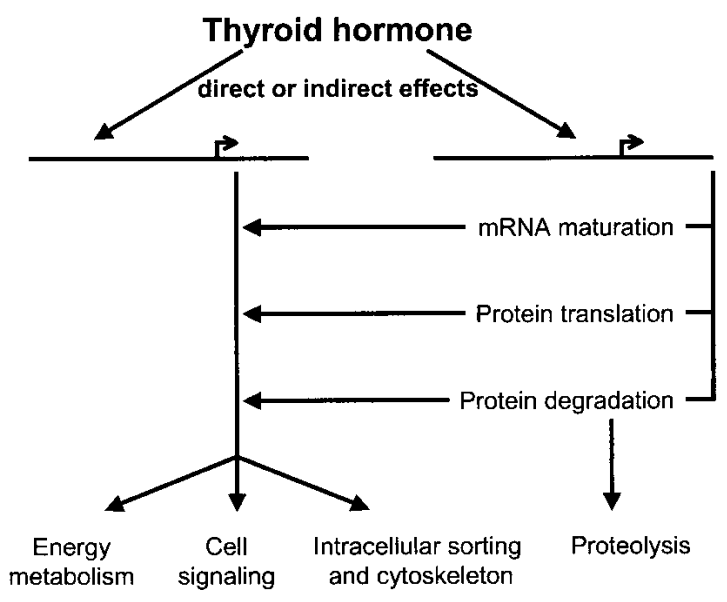

Figure 3 Summary of thyroid hormone regulation of gene expression in human skeletal muscle. The 14-day treatment with triiodothyronine induces direct and indirect effects on gene transcription. The hormone regulates genes with a wide range of cellular functions. Post-transcriptional regulation of protein expression also may contribute to the physiological and pathological action of thyroid hormone.

coregulations may contribute to the marked effect of T3 on skeletal muscle respiration (Tata et al. 1963).

Our study reveals that the transcriptional effect of T3 on skeletal muscle extends well beyond the classic metabolic effects of the hormone. Thirty-six signal transduction genes were up-regulated. Through induction of receptor, G protein, and protein kinase gene expression, thyroid hormone may exert its permissive effect on hormonal regulation of skeletal muscle metabolism. Moreover, T3 increased mRNA expression of catalytic and regulatory subunits of protein phosphatases 1 and 2A. T3 also may influence cellular trafficking and tissue remodeling through increased expression of genes involved in protein transport and maturation, cytoskeleton assembly, and exchange between intracellular organelles. Our data also identify 144 expressed sequence tags up-regulated by T3, which correspond to novel putative target genes.

\section{Up-Regulation of Transcription Factors and Cofactors} Thyroid hormone up-regulated non-specific factors promoting transcription such as two subunits of transcription elongation factor B that assist RNA polymerase II as an auxiliary elongation factor. T3 induced mRNA expression of histone deacetylase 2 and DNA methyltransferase 3A, which are involved in transcriptional repression. This may constitute an indirect pathway for thyroid hormone-mediated mRNA down-regulation. Furthermore, T3 treatment resulted in upregulation of nuclear factors involved in skeletal muscle transcriptional control. These effects may contribute to indirect control by T3 of numerous genes. MADS box transcription enhancer factor 2 and myogenic factor 6 are two transcription factors involved in the late skeletal muscle differentiation program (Braun et al. 1990; McDermott et al. 1993). LAZ3/Bcl6 is a transcriptional repressor important for myogenesis, possibly through the induction and stabilization of the withdrawal from the cell cycle (Albagli-Curiel et al. 1998). $\mathrm{C} / \mathrm{EBP} \beta$ is positively regulated by $\mathrm{T} 3$ in liver (MenendezHurtado et al. 1997). The transcription factor controls insulin signal transduction pathway in skeletal muscle (Wang et al. 2000b). The up-regulation of C/EBP $\beta$ in skeletal muscle therefore may contribute to the insulin-resistant state observed in thyrotoxicosis. The up-regulated genes also included nuclear receptor coactivator 4 , a coactivator of androgen receptor and peroxisome proliferator-activated receptor (Yeh and Chang 1996).

\section{Post-Transcriptional Control of Protein Turnover}

Exposure to increased plasma level of thyroid hormone had profound effects on genes controlling post-transcriptional mechanisms including mRNA maturation and protein translation. Several transcripts encoding ribonucleoproteins and splicing factors were up-regulated. T3 treatment induced an increase in mRNA for protein synthesis factors such as ribosomal proteins and translation initiation factors including elF1A that is required for maximal rate of protein biosynthesis (Fletcher et al. 1999). Our data show an elevated level of mRNAs of the ubiquitin/proteasome pathway (Table 4). The ATP-dependent proteolytic pathway is responsible for the rapid degradation of many enzymes, signal transduction proteins, and transcriptional regulators including TR. Interestingly, proteasome-mediated degradation may play a critical role in the transcriptional activation of TR (Dace et al. 2000). We found that T3 induced an increase in mRNAs for proteasome subunits including $\mathrm{C} 2, \mathrm{C} 6$, and D12, which are part of the $19 \mathrm{~S}$ complex of the $26 \mathrm{~S}$ regulatory particle. There was also an increase in proteasome subunit A1, A3, A4, and A5 mRNAs that are essential $\alpha$-type catalytic subunits of the $20 \mathrm{~S}$ particle. In addition, $\mathrm{T} 3$ also increased mRNA for enzymes of the ubiquitinylation complex such as ubiquitin-conjugating enzyme 2B and cullin 2. Branched chain keto acid dehydrogenase E1, the rate-limiting enzyme in the catabolism of the branched chain amino acids, was up-regulated (Shimomura et al. 1995). Thus, hyperthyroidism appears to be accompanied by coordinated adaptations leading to an enhanced capacity of the proteasome degradative system. Combined with the increase in mRNA for ubiquitin-specific proteases, these regulations may be responsible for the loss of body protein mass under thyrotoxicosis (Ramsay 1965). Accordingly, increased proteolysis in skeletal muscle of hyperthyroid rats is mainly mediated via the ubiquitin-proteasome pathway (Tawa et al. 1997).

\section{T3 Effect on Metabolism}

Thyroid hormones participate with insulin and catecholamines in the regulation of skeletal muscle metabolism. The antagonism to insulin action was illustrated by the mRNA increase of the $\mathrm{p} 85 \alpha$ phosphatidylinositol 3-kinase regulatory subunit. Indeed, mice lacking p85 $\alpha$ show increased insulin sensitivity (Terauchi et al. 1999; Fruman et al. 2000). Thyroid hormones enhance the effect of catecholamines. An induction of the $\beta_{2}$-adrenergic receptor mRNA was observed consistent with the positive effects of T3 observed in human adipose tissue (Viguerie et al. 2002) and rat liver (Feng et al. 2000). As shown in hepatocytes (Swierczynski et al. 1991; Betley et al. 1993), T3 up-regulated enzymes involved in gluconeogenesis and glycogen metabolism (Table 5). Numerous genes of mitochondrial energy metabolism were up-regulated, including several enzymes associated with the citric acid cycle. Pyruvate dehydrogenase is one of the major enzymes responsible for the regulation of homeostasis of carbohydrate fuels in mammals. Two subunits of the complex, E1 $\alpha$ and E3, were induced. An up-regulation of pyruvate dehydrogenase 
Table 4. Thyroid Hormone-Induced Up-Regulation of mRNA Expression for Genes of Protein Catabolism

\begin{tabular}{llr}
\hline UniGene no. & \multicolumn{1}{c}{ Encoded protein } & Fold \\
\hline Hs.9280 & Proteasome (prosome, macropain) subunit, $\beta$ type, 9 & 3.20 \\
Hs.61153 & Proteasome (prosome, macropain) 26S subunit, ATPase, 2 & 2.56 \\
Hs.79137 & Protein-L-isoaspartate (D-aspartate) O-methyltransferase & 2.15 \\
Hs.811 & Ubiquitin-conjugating enzyme E2B (RAD6 homolog) & 2.14 \\
Hs.77578 & Ubiquitin-specific protease 9, X chromosome & 2.10 \\
Hs.79357 & Proteasome (prosome, macropain) 26S subunit, ATPase, 6 & 2.06 \\
Hs.82159 & Proteasome (prosome, macropain) subunit, $\alpha$ type, 1 & 2.04 \\
Hs.4295 & Proteasome (prosome, macropain) 26S subunit, non-ATPase, 12 & 2.02 \\
Hs.12272 & Beclin-1 & 1.95 \\
Hs.76913 & Proteasome (prosome, macropain) subunit, $\alpha$ type, 5 & 1.93 \\
Hs.251531 & Proteasome (prosome, macropain) subunit, $\alpha$ type, 4 & 1.88 \\
Hs.86978 & Prolyl endopeptidase & 1.87 \\
Hs.78950 & Branched chain keto acid dehydrogenase E1, $\alpha$ polypeptide & 1.85 \\
Hs.167108 & Proteasome (prosome, macropain) subunit, $\alpha$ type, 3 & 1.83 \\
Hs.99819 & Ubiquitin-specific protease 16 & 1.81 \\
Hs.82919 & Cullin 2 & 1.79 \\
Hs.75981 & Ubiquitin-specific protease 14 (tRNA-guanine transglycosylase) & 1.74 \\
Hs.79357 & Proteasome (prosome, macropain) 26S subunit, ATPase, 6 & 1.68 \\
Hs.15303 & Protein similar to mouse ubiquitin-protein ligase E3- $\alpha$ & 1.66 \\
Hs.101408 & Branched chain aminotransferase 2, mitochondrial & 1.55 \\
\hline
\end{tabular}

The fold increase represents the mean of the five comparisons.

kinase 4, which is highly expressed in skeletal muscle, also was observed as shown in rat heart (Sugden et al. 2000). Phosphorylation of pyruvate dehydrogenase by the kinase results in inactivation and may be considered as an adaptive mechanism to enhance the use of fatty acids as an energy source. For the biogenesis of the respiratory apparatus, more than 100 proteins are necessary (Pillar and Seitz 1997). Most of them are encoded in the nucleus with only 13 being encoded by the mitochondrial genome. Among the 50 independent mRNAs representing respiratory chain proteins on the microarray, 13 were up-regulated during $\mathrm{T} 3$ treatment (Table 5) and seven of them were coexpressed in human tissues (Fig. 2B). The upregulated genes included several subunits of $\mathrm{NADH}$ : ubiquinone oxidoreductase (complex I) where proton translocation is coupled to electron transfer. Cytochrome c, a component of complex IV that donates electrons to the cytochrome oxidase complex, was markedly up-regulated as shown in rat skeletal muscle (Stevens et al. 1995). We observed an increase of two cytochrome oxidase (complex IV) and four ATP synthase (F1F0 ATPase or complex V) subunit mRNAs. The proteins of the respiratory chain need to be available in stoichiometric amounts for proper assembly in the inner mitochondrial membrane. T3 is a potent inducer of a subset of, but not all, nucleus-encoded respiratory chain genes (Wiesner et al. 1992). This suggests that thyroid hormone yields an increase of the other components, indirectly through posttranscriptional mechanisms. The increase in genes encoding protein translation factors (see above) may participate in this mechanism. Moreover, T3 induced genes involved in mitochondrial protein translation such as the only known mitochondrial translation initiation factor MTIF2 (Ma and Spremulli 1996) and mitochondrial ribosomal proteins S4, L3, and L19. Besides coupled respiration, thyroid hormones also increase uncoupled respiration and the leak of protons across the inner mitochondrial membrane (Lanni et al. 1999). In humans, T3 treatment of young adults for 3 days promotes in vivo mitochondrial energy uncoupling in skeletal muscle (Lebon et al. 2001). Here, we show that T3 induced three putative candidates to explain the uncoupling effect : uncoupling protein 3 and adenine nucleotide translocases 1 and 2 (Skulachev 1999). Genes of energy metabolism recently have been shown to be down-regulated during caloric restriction in vastus lateralis muscle of male rhesus monkeys (Kayo et al. 2001). Caloric restriction is characterized by a decrease in plasma thyroid hormone level that leads to a decrease of the metabolic rate. Our data therefore are consistent with a role of thyroid hormone in caloric restriction-induced changes in energy metabolism gene expression.

\section{Modulation of Cytoskeletal Protein Expression}

Thyroid hormone modulated expression of genes involved in the maintenance of cellular architecture. In human skeletal muscle, several adhesion complexes are essential for the organization of the actin cytoskeleton and maintenance of intercellular junctions (Chothia and Jones 1997). The mRNA for integrin $\alpha 5$ was up-regulated under T3. Integrins are receptors for extracellular matrix-mediated cytoskeletal organization and cell adhesion. Up-regulation also was observed for $\alpha$ and $\beta$-catenin mRNA. $\beta$-Catenin links the cadherin receptors to the actin cytoskeleton via $\alpha$-catenin. In striated muscle, the dystrophin-glycoprotein complex forms a critical link between the cytoskeleton and the extracellular matrix (Matsumura et al. 1999). The mRNAs of the glycoproteins dystroglycan 1 and $\beta$-sarcoglycan were upregulated. Ankyrins are protein linkers between the integral membrane proteins and spectrin-based cytoskeleton (Rubtsov and Lopina 2000). Through their interaction with cytoskeleton proteins such as vimentin or tubulin, they participate in the attachment of the intermediary filaments and microtubules to the membrane. In myocytes, ankyrin $G$ is the main ankyrin form. Both ankyrin $G$ and spectrin were positively regulated under T3. The expression of other molecules of the cytoskeleton was induced such as the actin-related protein ARPC2, tropomodulin, tubulin, and pinin, a desmosome-associated protein. Taken together, the up-regulation 
Table 5. Thyroid Hormone-Induced Up-Regulation of mRNA Expression for Genes Involved in Metabolism

\begin{tabular}{|c|c|c|c|}
\hline $\begin{array}{l}\text { UniGene } \\
\text { no. }\end{array}$ & Encoded protein & Pathway & Fold \\
\hline Hs.77837 & UDP-glucose pyrophosphorylase 2 & Glycogen synthesis & 3.02 \\
\hline Hs.1691 & Glycogen branching enzyme & Glycogen synthesis & 2.82 \\
\hline Hs.169428 & Cytochrome $\mathrm{c}^{\mathrm{a}}$ & Respiratory chain (complex IV) & 2.68 \\
\hline Hs.2043 & Adenine nucleotide translocase 1 & Mitochondrial carrier & 2.66 \\
\hline Hs.33084 & Fructose transporter GLUT $5^{a}$ & Glucose metabolism & 2.66 \\
\hline Hs.78713 & Adenine nucleotide translocase $2^{a}$ & Mitochondrial carrier & 2.58 \\
\hline Hs.74635 & Dihydrolipoamide dehydrogenase (pyruvate dehydrogenase complex E3) & Citric acid cycle & 2.58 \\
\hline Hs. 80595 & NADH dehydrogenase (ubiquinone) Fe-S protein 5 & Respiratory chain (complex I) & 2.54 \\
\hline Hs.8364 & Pyruvate dehydrogenase kinase, isoenzyme $4^{\mathrm{a}}$ & Citric acid cycle & 2.52 \\
\hline Hs.19236 & NADH dehydrogenase (ubiquinone) $1 \beta$ subcomplex, 5 & Respiratory chain (complex I) & 2.50 \\
\hline Hs.131255 & Ubiquinol-cytochrome $\mathrm{c}$ reductase binding protein & Respiratory chain (complex III) & 2.46 \\
\hline Hs.155433 & ATP synthase, F1 complex, $\gamma 1$ & Respiratory chain (complex V) & 2.35 \\
\hline Hs.101337 & Uncoupling protein $3^{a}$ & Mitochondrial carrier & 2.30 \\
\hline Hs. 81634 & ATP synthase, F0 complex, subunit b, isoform 1 & Respiratory chain (complex V) & 2.26 \\
\hline Hs.109646 & NADH dehydrogenase (ubiquinone) $1 \beta$ subcomplex, 6 & Respiratory chain (complex I) & 2.23 \\
\hline Hs. 61255 & Fructose-1,6-bisphosphatase $2^{a}$ & Neoglucogenesis & 2.13 \\
\hline Hs. 1023 & Pyruvate decarboxylase (pyruvate dehydrogenase complex E1- $\alpha$ ) & Citric acid cycle & 2.10 \\
\hline Hs.429 & ATP synthase, FO complex, subunit $c$, isoform 3 & Respiratory chain (complex V) & 2.09 \\
\hline Hs.79876 & Steroid sulfatase, arylsulfatase $C$, isozyme $S^{a}$ & Steroid hormone synthesis & 2.02 \\
\hline Hs.73851 & ATP synthase, F0 complex, subunit F6 & Respiratory chain (complex V) & 2.02 \\
\hline Hs.78060 & Phosphorylase kinase, $\beta$ & Glycogenolysis & 2.00 \\
\hline Hs.268012 & Long-chain fatty acid-coenzyme A ligase 3 & Lipid $\beta$ oxidation & 1.99 \\
\hline Hs.7043 & Succinate-CoA ligase, GDP-forming, $\alpha$ subunit & Citric acid cycle & 1.99 \\
\hline Hs.74823 & NADH dehydrogenase (ubiquinone) $1 \alpha$ subcomplex, 1 & Respiratory chain (complex I) & 1.96 \\
\hline Hs. 3462 & Cytochrome $\mathrm{c}$ oxidase subunit VIlc & Respiratory chain (complex IV) & 1.90 \\
\hline Hs.76688 & Carboxylesterase 1 & Cholesterol metabolism & 1.86 \\
\hline Hs.183435 & NADH dehydrogenase (ubiquinone) $1 \beta$ subcomplex, 1 & Respiratory chain (complex I) & 1.82 \\
\hline Hs.74649 & Cytochrome $\mathrm{c}$ oxidase subunit $\mathrm{VIc}^{\mathrm{a}}$ & Respiratory chain (complex IV) & 1.74 \\
\hline Hs.77508 & Glutamate dehydrogenase $1^{a}$ & Citric acid cycle & 1.72 \\
\hline Hs. 177584 & 3-oxoacid CoA transferase & Citric acid cycle & 1.64 \\
\hline
\end{tabular}

The fold increase represents the mean of the five comparisons.

aproteins that have been shown to be positively regulated by thyroid hormones in rodents.

of genes encoding proteins of various adhesion complexes may contribute to skeletal muscle remodeling under thyrotoxicosis.

\section{Conclusion}

In this article, we have characterized a transcriptional profile in response to $\mathrm{T} 3$ in vivo. Sorting of up-regulated genes into functional classes and determination of common expression patterns in human tissues defined the molecular signatures that underlie the pleiotropic effect of thyroid hormone in human skeletal muscle (Fig. 3). In line with the known physiological effects of T3, induction of many genes involved in protein turnover and energy metabolism was observed. The study also reveals novel target cellular pathways. The impact on these pathways may help to understand the permissive effect of T3 on signal transduction cascades, intracellular transport, and tissue remodeling. This study also illustrates the value of a coupled use of DNA microarrays with microbiopsies from human tissues to study in vivo the physiological and pathological action of hormones.

\section{METHODS}

\section{Subjects and Clinical Protocol}

Nine healthy male Caucasian volunteers (22-33 years old) were recruited. The study was performed according to the
Huriet Law and INSERM Good Clinical Practice guidelines. The protocol was approved by the Ethics Committee of Toulouse University Hospitals. Written informed consent was obtained from the subjects. All the visits and investigations were performed at the Toulouse Clinical Investigation Center. The same investigations were performed at day 0 and day 14 . Participants were instructed to take one tablet of $25 \mu \mathrm{g}$ of T3 (Cynomel; Marion Merell) three times a day (75 $\mu \mathrm{g}$ per day) during 14 days. No concurrent medication was allowed during the course of the study. The subjects were instructed by a dietitian to continue with their usual diet. After an overnight fast, a catheter was inserted at 8 a.m. into the antecubital vein for blood sampling and kept patent with isotonic saline. Three 10-min interval blood samples were drawn for determinations of metabolic and hormonal parameters. Heart rate and blood pressure were measured at three 10-min intervals using an automated blood pressure monitor. After a 1-h resting period in supine position, oxygen consumption $\left(\mathrm{VO}_{2}\right)$ and carbone dioxide production $\left(\mathrm{VCO}_{2}\right)$ were monitored over 30 min using an open-circuit ventilated-canopy system (Deltatrac II monitor; Datex Instrumentarium Corp.) calibrated with a reference gas. Resting metabolic rate was derived from $\mathrm{VO}_{2}$ and $\mathrm{VCO}_{2}$ using indirect calorimetry. Then, a percutaneous biopsy of the vastus lateralis muscle was performed using Weil Blakesley pliers. Approximately $3 \mathrm{~mL} 1 \%$ lidocaine (Xylocaine; Astra France) was injected into the skin and superficial tissue before the biopsy. The procedure involved a $5-\mathrm{mm}$ incision through the skin and muscle sheath 15-20 cm above the knee. Muscle samples were flashfrozen in liquid nitrogen and stored at $-80^{\circ} \mathrm{C}$ until analysis. On day 14, biopsies were performed on the contralateral 
side. Before and at the end of the treatment period, body composition was assessed by dual-energy X-ray absorptiometry performed with a total body scanner (DPX, software 3.6; Lunar Radiation Corp.).

\section{mRNA Quantitation}

Total RNA was extracted using the RNA STAT-60 isolation reagent (Tel-Test). Real-time, quantitative RT-PCR was performed on GeneAmp 5700 Sequence Detection System (Applied Biosystems). A set of primers was designed for each gene using the software Primer Express 1.5 (Applied Biosystems). Amplicons of $65-90$ base pairs with Tm between 79 and $82^{\circ} \mathrm{C}$ were selected. Reverse transcription was performed with $1 \mu \mathrm{g}$ of total RNA for each biopsy, and 10 ng of cDNA was used as template for real-time PCR as recommended by the manufacturer. A dissociation curve was generated at the end of the PCR cycles to verify that a single gene product was amplified. A standard curve for each primer pair was obtained using serial dilutions of human skeletal muscle cDNA. We used $18 \mathrm{~S}$ ribosomal RNA as control to normalize gene expression using the Ribosomal RNA Control TaqMan Assay kit (Applied Biosystems).

\section{RNA Amplification and Microarray Experiments}

Because the amount of total RNA obtained from skeletal muscle microbiopsies is limited, we used a two round amplification protocol to produce aRNA from total RNA (Wang et al. 2000a). The method, which is not based on PCR, ensures high-fidelity mRNA amplification. We prepared the aRNAs from $1.5 \mu \mathrm{g}$ of total RNA in DNase-free water containing $1 \mu \mathrm{g}$ of oligo-dT(15)-T7 primer. After denaturation, T7 bacteria phage promoter was incorporated into cDNA in a reverse transcription reaction containing a template-switch primer. cDNA synthesis was obtained after $90 \mathrm{~min}$ at $42^{\circ} \mathrm{C}$. Full-length cDNA was synthesized by adding DNase-free water, Advantage PCR buffer and cDNA polymerase (Clontech), dNTPs, and RNase $\mathrm{H}$ (Promega). Reactions were terminated by incubation in a $1 \mathrm{M} \mathrm{NaOH}$ solution with $2 \mathrm{mM}$ EDTA at $65^{\circ} \mathrm{C}$. After cDNA extraction by phenol-chloroform-isoamyl alcohol and ethanol precipitation, cDNAs were resuspended in $60 \mu \mathrm{L}$ water, passed through a Bio- 6 chromatography column (Bio$\mathrm{Rad})$ and washed. In vitro transcription at $37^{\circ} \mathrm{C}$ for $6 \mathrm{~h}$ was performed using the T7 Megascript Kit (Ambion). RNA recovery was achieved by TRIzol purification (Life Technologies). Then, aliquots of aRNA $(1 \mu \mathrm{g})$ were reverse-transcribed into cDNA using $2 \mu \mathrm{g}$ of random hexamers. The reaction mixture was heated to $65^{\circ} \mathrm{C}$ for $10 \mathrm{~min}$, and the synthesis was continued at $42^{\circ} \mathrm{C}$ for $90 \mathrm{~min}$ with Superscript II (Life Technologies). A second-strand cDNA synthesis and the in vitro transcription of aRNA were conducted as for the first round. Detail protocols of the hybridization and scanning procedure are described at http://cmgm.stanford.edu/pbrown/protocols/ index.html. Briefly, $6 \mu \mathrm{g}$ of aRNA was labeled by incorporating a Cy dye during the random primed reverse transcription with Superscript II. Amplified RNA from individuals before T3 administration were labeled with Cy3 and aRNA from individuals after T3 were labeled with Cy5, except for one subject with an inversed labeling. The labeled cDNA mixture was concentrated using microcon 30 column (Millipore) after the addition of human cot-1 DNA (Life Technologies). After denaturation, the probe was added to the array, which was covered by a Coverslip. The slide then was placed in a sealed humidified hybridization chamber for a $16-\mathrm{h}$ hybridization at $65^{\circ} \mathrm{C}$. Slides were washed twice in $2 \times$ SSC $0.1 \%$ SDS, $1 \times$ SSC, and then $0.5 \times$ SSC. The arrays were immediately scanned using a GenePix 4000A confocal Scanner (Axon Instruments). Images were analyzed using GenePix pro 3 software. Data files generated by Genepix were entered into the Stanford Microarray Database (http://genome-www4.stanford.edu/MicroArray/
SMD/). We applied a uniform scale factor to all measured intensities that normalized signal intensities between the two fluorescent images. This normalization factor was chosen so that the mean $\log _{2}$ (Cy5/Cy3) for a subset of good-quality spots $(\sim 16,000$ spots) was 0 .

\section{Data Analysis}

Before extraction of $\log _{2}$ ratio data, we applied a filtering procedure by omitting manually flagged elements (i.e., badquality spots). After also eliminating the spots with an average intensity below 1.5 -fold above the background, 22,640 spots were recovered. The overall background was low because $85.5 \%$ of the spots had channel intensities fourfold above the background. To assess reproducibility of two hybridizations after independent amplifications, we compared aRNA preparations labeled with Cy3 and Cy5 from two different individuals before the treatment. The correlation coefficient between Cy3-labeled aRNA and Cy5-labeled aRNA was 0.93. We then extracted the $\log _{2}$ Cy5/Cy3 ratios (treated/untreated) for the five experiments. cDNA with missing data were excluded. Data were analyzed using the SAM procedure, a validated statistical technique for identifying differentially expressed genes across high-density microarrays (Tusher et al. 2001). Before calculations, the data from each of the five experiments were normalized in log-space to have mean 0 and standard deviation 1. In the SAM procedure, the modified t-statistic $d(i)=x(i) /\left[s(i)+S_{0}\right]$ is calculated for the $i^{\text {th }}$ gene, where $\mathrm{x}(\mathrm{i})$ is the mean of the $\log _{2}$ ratio data across all five experiments, and $s(\mathrm{i})$ is the appropriately scaled standard deviation. The quantity $S_{0}$ is an adjustment factor derived from the data, which attempts to make d(i) independent of $s(i)$. Because the null hypothesis was that there was no treatment effect, we tested whether the expected value of the $\log _{2}$ ratio is 0 in the statistic $d(i)$. SAM is a nonparametric procedure that compares the ordered d(i) to the expected value of the ordered statistics calculated under random assignment of treatment in the $\log _{2}$ ratio and calls genes significant based on this comparison. Testing all genes simultaneously requires one to implement a multiple comparison procedure, which guards against many false-positives. The FDR method controls the expected value of the ratio of the number of false-positives to the total number of genes called significant (Benjamini and Hochberg 1995). SAM provides a point estimate of the FDR based on the number of significant genes in randomized data and the original data. Details on the SAM procedure is available at http://www-stat.stanford.edu/ tibs/SAM/index.html. With an estimated FDR of $15 \%, 449$ cDNA were selected as being differentially expressed. The channel intensities for this set of genes were more than twofold above the background, and $74 \%$ of them had channel intensities at least sixfold above the background. For $154 \mathrm{cDNAs}$ with replicates among the 18,705 cDNAs, that is, the same UniGene number, we tested, using Student's $t$-test, whether the expected value of the $\log _{2}$ ratio was 0 .

\section{Coexpression of T3-Regulated Genes in Various Tissues and Cell Lines}

We analyzed how the 403 transcripts might be coexpressed together in 19 human adult tissues and cell lines. Each tissue or cell line polyA ${ }^{+}$RNA-labeled with Cy5 was hybridized against a common reference pool consisting of 11 different cell lines described elsewhere (Perou et al. 2000). We extracted the Cy5/Cy3 ratios for the 403 transcripts and applied twodimensional hierarchical clustering to the expression data (Eisen et al. 1998). Data were centered to the mean by subtracting the arithmetic mean of all ratios measured for each gene. We performed a hierarchical cluster analysis on both genes and experiments using the Pearson correlation coefficient as a 
measure of similarities and average linkage clustering. The results were visualized by the Tree view software (http:// rana.lbl.gov/).

\section{ACKNOWLEDGMENTS}

We thank Sandrine Dudoit (Department of Biochemistry, Stanford University) and Rob Tibshirani (Department of Statistics, Stanford University) for discussion and advice on statistical analyses of microarray data. This work was supported by grants from INSERM (99CICTO06 and PROGRES 4P007E to D.L.), ALFEDIAM/Novo-Nordisk (to D.L.), ALFEDIAM/Institut Lilly (to K.C.), and Institut de Recherches Servier (to K.C.). M.D. and A.A were supported by MSTP fellowships (National Institute of General Medical Sciences Grant 5T32 GM07365). G.S.B. and P.O.B. are Associate Investigators of the HHMI. We thank Drs. Ricquier (CNRS, Meudon) and Lafontan (INSERM, Toulouse) for critical reading of the manuscript.

The publication costs of this article were defrayed in part by payment of page charges. This article must therefore be hereby marked "advertisement" in accordance with 18 USC section 1734 solely to indicate this fact.

\section{REFERENCES}

Albagli-Curiel, O., Dhordain, P., Lantoine, D., Aurade, F., Quief, S. Kerckaert, J.P., Montarras, D., and Pinset, C. 1998. Increased expression of the LAZ3 (BCL6) proto-oncogene accompanies murine skeletal myogenesis. Differentiation 64: 33-44.

Barbe, P., Larrouy, D., Boulanger, C., Chevillotte, E., Viguerie, N., Thalamas, C., Oliva Trastoy, M., Roques, M., Vidal, H., and Langin, D. 2001. Triiodothyronine-mediated upregulation of UCP2 and UCP3 gene expression in human skeletal muscle without coordinated induction of mitochondrial respiratory chain genes. FASEB J. 15: 13-15.

Benjamini, Y. and Hochberg, Y. 1995. Controlling the false discovery rate: A practical and powerful approach of multiple testing. J. R. Stat. Soc. Ser. B. 57: 289-300.

Betley, S., Peak, M., and Agius, L. 1993. Triiodo-L-thyronine stimulates glycogen synthesis in rat hepatocyte cultures. Mol. Cell. Biochem. 120: 151-158.

Bortoluzzi, S., d'Alessi, F., Romualdi, C., and Danieli, G.A. 2000. The human adult skeletal muscle transcriptional profile reconstructed by a novel computational approach. Genome Res. 10: 344-349.

Braun, T., Bober, E., Winter, B., Rosenthal, N., and Arnold, H.H. 1990. Myf-6, a new member of the human gene family of myogenic determination factors: Evidence for a gene cluster on chromosome 12. EMBO J. 9: 821-831.

Chothia, C. and Jones, E.Y. 1997. The molecular structure of cell adhesion molecules. Annu. Rev. Biochem. 66: 823-862.

Dace, A., Zhao, L., Park, K.S., Furuno, T., Takamura, N., Nakanishi, M., West, B.L., Hanover, J.A., and Cheng, S. 2000. Hormone binding induces rapid proteasome-mediated degradation of thyroid hormone receptors. Proc. Natl. Acad. Sci. 97: 8985-8990.

Dauncey, M.J. 1990. Thyroid hormones and thermogenesis. Proc. Nutr. Soc. 49: 203-215.

Eisen, M.B., Spellman, P.T., Brown, P.O., and Botstein, D. 1998. Cluster analysis and display of genome-wide expression patterns. Proc. Natl. Acad. Sci. 95: 14863-14868.

Feng, X., Jiang, Y., Meltzer, P., and Yen, P.M. 2000. Thyroid hormone regulation of hepatic genes in vivo detected by complementary DNA microarray. Mol. Endocrinol. 14: 947-955.

Fletcher, C.M., Pestova, T.V., Hellen, C.U.T., and Wagner, G. 1999 Structure and interactions of the translation initiation factor elF1. EMBO J. 18: 2631-2637.

Freake, H.C. and Oppenheimer, J.H. 1995. Thermogenesis and thyroid function. Annu. Rev. Nutr. 15: 263-291.

Fruman, D.A., Mauvais-Jarvis, F., Pollard, D.A., Yballe, C.M., Brazil, D., Bronson, R.T., Kahn, C.R., and Cantley, L.C. 2000. Hypoglycaemia, liver necrosis and perinatal death in mice lacking all isoforms of phosphoinositide 3-kinase p85 alpha. Nat. Genet. 26: 379-382.

Gong, D.W., He, Y., Karas, M., and Reitman, M. 1997. Uncoupling protein-3 is a mediator of thermogenesis regulated by thyroid hormone, $\beta 3$-adrenergic agonists, and leptin. J. Biol. Chem. 272: $24129-24132$.

Harrington, C.R. 1935. Biochemical basis of thyroid function. Lancet
1: $1199-1204$.

Kayo, T., Allison, D.B., Weindruch, R., and Prolla, T.A. 2001. Influences of aging and caloric restriction on the transcriptional profile of skeletal muscle from rhesus monkeys. Proc. Natl. Acad. Sci. 98: 5093-5098.

Lanni, A., Beneduce, L., Lombardi, A., Moreno, M., Boss, O., Muzzin, P., Giacobino, J.P., and Goglia, F. 1999. Expression of uncoupling protein-3 and mitochondrial activity in the transition from hypothyroid to hyperthyroid state in rat skeletal muscle. FEBS Lett. 444: 250-254.

Lebon, V., Dufour, S., Petersen, K.F., Ren, J., Jucker, B.M., Slezak L.A., Cline, G.W., Rothman, D.L., and Shulman, G.I. 2001. Effect of triiodothyronine on mitochondrial energy coupling in human skeletal muscle. J. Clin. Invest. 108: 733-737.

Ma, J. and Spremulli, L.L. 1996. Expression, purification, and mechanistic studies of bovine mitochondrial translational initiation factor 2. J. Biol. Chem. 271: 5805-5811.

Matsumura, K., Saito, F., Yamada, H., Hase, A., Sunada, Y., and Shimizu, T. 1999. Sarcoglycan complex: A muscular supporter of dystroglycan-dystrophin interplay? Cell. Mol. Biol. 45: 751-762.

McDermott, J.C., Cardoso, M.C., Yu, Y.T., Andres, V., Leifer, D., Krainc, D., Lipton, S.A., and Nadal-Ginard, B. 1993. hMEF2C gene encodes skeletal muscle- and brain-specific transcription factors. Mol. Cell. Biol. 13: 2564-2577.

Menendez-Hurtado, A., Vega-Nunez, E., Santos, A., and Perez-Castillo, A. 1997. Regulation by thyroid hormone and retinoic acid of the CCAAT/enhancer binding protein $\alpha$ and $\beta$ genes during liver development. Biochem. Biophys. Res. Commun. 234: $605-610$.

Perou, C.M., Sorlie, T., Eisen, M.B., van de Rijn, M., Jeffrey, S.S., Rees, C.A., Pollack, J.R., Ross, D.T., Johnsen, H., Akslen, L.A., et al. 2000. Molecular portraits of human breast tumours. Nature 406: $747-752$.

Pietu, G., Eveno, E., Soury-Segurens, B., Fayein, N.A., Mariage-Samson, R., Matingou, C., Leroy, E., Dechesne, C., Krieger, S., Ansorge, W., et al. 1999. The genexpress IMAGE knowledge base of the human muscle transcriptome: A resource of structural, functional, and positional candidate genes for muscle physiology and pathologies. Genome Res. 9: 1313-1320.

Pillar, T.M. and Seitz, H.J. 1997. Thyroid hormone and gene expression in the regulation of mitochondrial respiratory function. Eur. J. Endocrinol. 136: 231-239.

Ramsay, I.D. 1965. Electromyography in thyrotoxicosis. Q. J. Med. 34: $255-267$.

Rooyackers, O.E. and Sreekumaran Nair, K. 1997. Hormonal regulation of human muscle protein metabolism. Annu. Rev. Nutr. 17: 457-485.

Rubtsov, A.M. and Lopina, O.D. 2000. Ankyrins. FEBS Lett. 482: 1-5.

Shimomura, Y., Fujii, H., Suzuki, M., Murakami, T., Fujitsuka, N., and Nakai, N. 1995. Branched-chain $\alpha$-keto acid dehydrogenase complex in rat skeletal muscle: Regulation of the activity and gene expression by nutrition and physical exercise. J. Nutr. 125: $1762 S-1765 S$

Skulachev, V.P. 1999. Anion carriers in fatty acid-mediated physiological uncoupling. J. Bioenerg. Biomembr. 31: 431-445.

Stevens, R.J., Nishio, M.L., and Hood, D.A. 1995. Effect of hypothyroidism on the expression of cytochrome $\mathrm{c}$ and cytochrome c oxidase in heart and muscle during development. Mol. Cell. Biochem. 143: 119-127.

Sugden, M.C., Langdown, M.L., Harris, R.A., and Holness, M.J. 2000. Expression and regulation of pyruvate dehydrogenase kinase isoforms in the developing rat heart and in adulthood: Role of thyroid hormone status and lipid supply. Biochem. J. 352: 731-738.

Swierczynski, J., Mitchell, D.A., Reinhold, D.S., Salati, L.M., Stapleton, S.R., Klautky, S.A., Struve, A.E., and Goodridge, A.G. 1991. Triiodothyronine-induced accumulations of malic enzyme, fatty acid synthase, acetyl-coenzyme A carboxylase, and their mRNAs are blocked by protein kinase inhibitors. Transcription is the affected step. J. Biol. Chem. 266: 17459-17466.

Tata, J.R., Ernster, L., Lindberg, O., Arhenius, E., Pedersen, S., and Hedman, R. 1963. The action of thyroid hormones at the cellular level. Biochem. J. 86: 408-428.

Tawa, N.E., Odessey, R., and Goldberg, A.L. 1997. Inhibitors of the proteasome reduce the accelerated proteolysis in atrophying rat skeletal muscles. J. Clin. Invest. 100: 197-203.

Terauchi, Y., Tsuji, Y., Satoh, S., Minoura, H., Murakami, K., Okuno, A., Inukai, K., Asano, T., Kaburagi, Y., Ueki, K., et al. 1999. Increased insulin sensitivity and hypoglycaemia in mice lacking 
the p85 alpha subunit of phosphoinositide 3-kinase. Nat. Genet. 21: 230-235.

Tusher, V.G., Tibshirani, R., and Chu, G. 2001. Significance analysis of microarrays applied to the ionizing radiation response. Proc. Natl. Acad. Sci. 98: 5116-5121.

Viguerie, N., Millet, L., Avizou, S., Vidal, H., Larrouy, D., and Langin, D. 2002. Regulation of human adipocyte gene expression by thyroid hormone. J. Clin. Endocrinol. Metab., in press.

Wang, E., Miller, L.D., Ohnmacht, G.A., Liu, E.T., and Marincola, F.M. 2000a. High-fidelity mRNA amplification for gene profiling. Nat. Biotechnol. 18: 457-459.

Wang, L., Shao, J., Muhlenkamp, P., Liu, S., Klepcyk, P., Ren, J., and Friedman, J.E. 2000b. Increased insulin receptor substrate-1 and enhanced skeletal muscle insulin sensitivity in mice lacking CCAAT/enhancer-binding protein $\beta$. J. Biol. Chem. 275: $14173-14181$.

Wiesner, R.J., Kurowski, T.T., and Zak, R. 1992. Regulation by thyroid hormone of nuclear and mitochondrial genes encoding subunits of cytochrome-c oxidase in rat liver and skeletal muscle. Mol. Endocrinol. 6: 1458-1467.

$\mathrm{Wu}, \mathrm{Y}$. and Koenig, R.J. 2000. Gene regulation by thyroid hormone. Trends Endocrinol. Metab. 11: 207-211.

Yeh, S. and Chang, C. 1996. Cloning and characterization of a specific coactivator, ARA70, for the androgen receptor in human prostate cells. Proc. Natl. Acad. Sci. 93: 5517-5521.

Zhang, J. and Lazar, M.A. 2000. The mechanism of action of thyroid hormones. Annu. Rev. Physiol. 62: 439-466.

Zurlo, F., Larson, K., Bogardus, C., and Ravussin, E. 1990. Skeletal muscle metabolism is a major determinant of resting energy expenditure. J. Clin. Invest. 86: 1423-1427.

\section{WEB SITE REFERENCES}

http://cmgm.stanford.edu/pbrown/protocols/index.html, detailed protocols of the hybridization and scanning procedures.

http://genome-www4.stanford.edu/MicroArray/SMD/, data files generated by Genepix as entered into the Stanford Microarray Database.

http://www-stat.stanford.edu/ tibs/SAM/index.html, details on the SAM procedure.

http://rana.lbl.gov/, results of the performed hierarchical cluster analysis on both genes and experiments using the Pearson correlation coefficient as a measure of similarities and average linkage clustering, as visualized by Tree view software.

Received July 26, 2001; accepted in revised form November 30, 2001. 


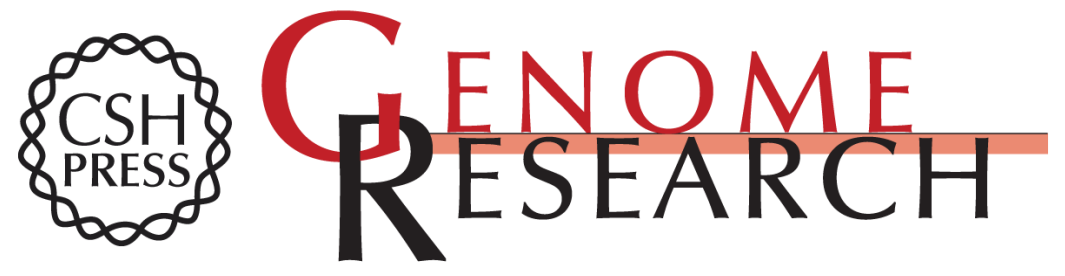

\section{In Vivo Regulation of Human Skeletal Muscle Gene Expression by Thyroid Hormone}

Karine Clément, Nathalie Viguerie, Maximilian Diehn, et al.

Genome Res. 2002 12: 281-291

Access the most recent version at doi:10.1101/gr.207702

Supplemental http://genome.cshlp.org/content/suppl/2002/04/07/12.2.281.DC1

Material

References This article cites 41 articles, 15 of which can be accessed free at:

http://genome.cshlp.org/content/12/2/281.full.html\#ref-list-1

\section{License}

Email Alerting Receive free email alerts when new articles cite this article - sign up in the box at the Service top right corner of the article or click here.

\section{Affordable, Accurate Sequencing.}

To subscribe to Genome Research go to: https://genome.cshlp.org/subscriptions 